\title{
A Suitable Business Model for Bank Branches: Combining Business Model and Malmquist Productivity Index (MPI)
}

\author{
Balal Karimi*, Mostafa Davtalab-Olyaie and Ali Abdali Abdali
}

Department of Mathematics, Karaj Branch, Islamic Azad University, Karaj, Iran

\begin{abstract}
In the recent years, more competitive business area has been used in various industries. According to the researches in the business fields, to achieve a competitive position for the company, it is necessary to use a suitable business model with high performance quality. Using a successful business model is a better choice in comparison with the other available options. But using an unsuitable business model may due to damage for the company. To identify a suitable business model, we use Malmquist productivity index (MPI), which is an economic indicator. To do this, we first propose a business model for commercial bank branches in Iran. We then calculate the productivity progress of each branch after carrying out our proposed business model using MPI. This index will be obtained using data envelopment analysis. This method is the first method to combine business model and MPI for developing an assessment model in business, which is stronger than other existent models. Finally, this method is implemented on a sample of statistical population including 40 bank branches in Iran.
\end{abstract}

Keywords: Business model; Total factor productivity (TFP); Malmquist productivity index (MPI); Data envelopment analysis

\section{Introduction}

In the economy, banks as the base of the financial institutions have important tasks such as mobilizing the savings, intermediation, facilitating flow of payments, allocation of credits, restoring order, and so on. Specially, in developing countries with less developed financial markets and assets, banks are powerful institutions that are able to implement intermediation and help to reduce the risk of investments by doing their tasks. This means that bank has the main task in providing funds of long-term and medium-term economic programs of these communities because of the intermediation role in money market and due to the lack of adequate development of the capital market. On the other hand, according to the process of liberalization of markets, relation with global market, and also importance of improve financial standards in these communities, we need to use precise criteria for evaluating the effectiveness of the banks.

The term business model has almost entered in management literature since four decades ago. The first people who used the term business models are Konczal [1] and Dottore [2]. They used this word about the concept of modeling processes and data.

By reviewing the literature of the business model, one can be found many definitions of this concept. Business model includes the general words about the choice of customers, job outsourcing, combining resources, going to market, creating utility for customers and gaining profit [3]. In other definition by Petrovic et al. [4] business model is consistent with creating real value that supports the real processes of the company. Faber et al., considered business model as a network of companies that their aim is create value through the deployment of technology opportunities [5]. They have balanced and reconciled based on differences in technical choices, user, organization and financial requirements [6]. Chesbrough and Rosenbloom [7] also believed that successful business models link the technological capabilities with their real economic value by creating innovative logic. Teece considered business model as a good which reflects management's hypothesis about what customers need, and how a company can best meet and provide these needs [8].

In this paper, we first propose a business model for commercial bank branches. Then, we use an economic indicator in order to measure the validity of our proposed model. This indicator in the economy is known as Malmquist productivity index (MPI) and it is one of the leading indicators in the economy [9]. In fact, we use this economic indicator to know how the productivity progress of the branches after carrying out our proposed business model. To do this, the indexes of our proposed model are first divided into two input and output variables. We then use data envelopment analysis (DEA) to calculate MIP index for assessing the productivity progress of each branch after carrying out our business model [10].

DEA is a mathematical technique to evaluate the performance of decision making units (DMUs) with multiple inputs and multiple outputs [11]. DMUs can include bank branches, hospitals and etc. [12]. Many articles are done about bank performance assessment by DEA [13-16].

The rest of this manuscript is organized as follows. In Section 2 we propose business model of bank branches. We propose a method to measure the productivity enhancement of each branch after implementing our proposed business model in section 3. In the next section, our proposed method is implemented on a sample of 40 branches of the commercial bank. The conclusion and future directions for research are summarized in the last section.

\section{Proposing a Business Model for Branches of Bank}

The concept of a business model facilitates analysis of the way in which a firm derives economic value from a newly developed technology. Indeed Chesbrough and Rosenbloom have argued that it is

${ }^{*}$ Corresponding author: Karimi B, Department of Mathematics, Kara Branch, Islamic Azad University, Karaj, Iran, Tel: +98 263441 8143; E-mail: b.karimi1987@gmail.com

Received April 01, 2018; Accepted April 12, 2018; Published April 19, 2018

Citation: Karimi B, Davtalab-Olyaie M, Abdali AA (2018) A Suitable Business Model for Bank Branches: Combining Business Model and Malmquist Productivity Index (MPI). Bus Eco J 9: 348. doi: 10.4172/2151-6219.1000348

Copyright: $\odot 2018$ Karimi B, et al. This is an open-access article distributed under the terms of the Creative Commons Attribution License, which permits unrestricted use, distribution, and reproduction in any medium, provided the original author and source are credited. 
Citation: Karimi B, Davtalab-Olyaie M, Abdali AA (2018) A Suitable Business Model for Bank Branches: Combining Business Model and Malmquist Productivity Index (MPI). Bus Eco J 9: 348. doi: 10.4172/2151-6219.1000348

the business model adopted, more so than the technology itself, which is critical to the success of the commercialization of new technology [7]. These business models are used with different approaches in small and large companies, for example Google Company.

We here introduce a business model for bank branches. In line with unification of performance appraisal indexes of branches using the presented model, we can monitor and measure the performance of the branches in the field of variable payments (market development and remuneration); and consequently, we can lead bank to develop profitability.

In this model, profitability is the main focus. That is, the cost on one side and revenue of branch has been considered on the other side (shared and non-shared revenue). For comprehensiveness and completeness of all aspects of bank's activities as an economic institution, qualitative criteria including credit quality has been considered in this model. The business model has been presented in Figure 1. The definitions of each indicator and its preferred weight have been provided as follows. In fact, business model provides an index for comparing and classifying branches based on their performance. For each branch, this index is calculated by sum of the multiplications of indicators to their preferred weight.

\section{Credit Quality}

This indicator is composed of two categories of indicators, the ratio of deferred to loans and shared revenues. The assigned preferred weight of this indicator is 25 scores.

\section{The ratio of deferred to loans ( 5 Score)}

With the increase in lending we can achieve profitability, but if the quality of loans not considered, the lack of repayments leads banks to have difficulties. Therefore, the ratio of deferred to loans can monitor a part of risk associated with credit quality of loans as an index.

\section{Shared revenues (20 Score)}

This indicator is composed of two parts, loans and surplus resources revenues. Branch loans revenues are extracted through the relevant heading in the balance of branches. Surplus resources are calculated by multiplication of subtracting resources of branches (including legal deposit) and the balance of the loan to the rate of the profitability of the branch. The branch profitability ratio is also extracted from the difference between the base rate and the rate of equipment (cost to resources), where the base rate is the highest rate in terms of the bank which can be profitable.

\section{Services Quality}

Service quality has the highest preferred weight, 50 scores. This indicator includes the ratio of e-banking transaction to total transactions and non-shared revenues.

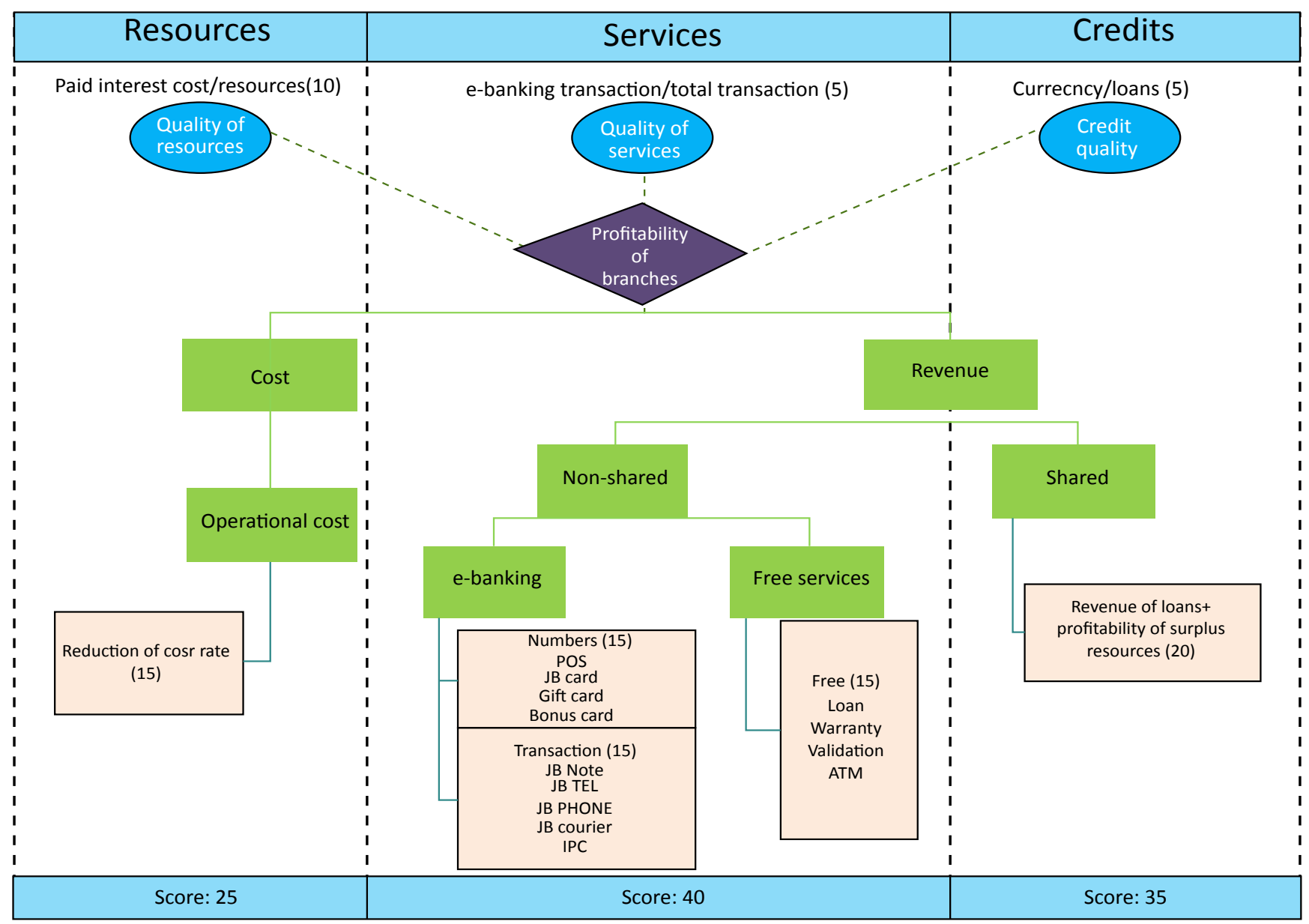

Figure 1: Business model of bank branches. 


\section{The ratio of e-banking transaction to total transactions (5 score)}

With the increase in service fees, non-shared revenues of bank will increase; but if the quality of service -the usage of new services and new platforms to serve - is less used the gradually make clients to approach rivals. Moreover, manual transactions that require physical activities by users can lead to increase the clients of traditional banking which results in burnout of personnel. Also the costs of electronic transactions are far less than traditional banking transactions.

\section{Non-shared revenues (45 score)}

Non-shared revenue includes three below indicators.

Fee indices (15 score): These indices are composed of the loan, warranty, validation, Performance of ATM and etc. Note that service fees, including loan, warrant can be recognized in headings of fees and miscellaneous revenue in balance of branches.

Number indices (15 score): These indices include gift cards, bonus cards, JB card, and POS devices. These mentioned indices provide the service to customers. Therefore, branches should identify customer needs and increase the ability of persuasion and sales. Thus, the number of successful marketing can be considered as an indicator of the assessment.

Transaction indicators (15 score): These indices include internet bank, mobile bank, telephone bank, and IPG. These mentioned indicators are the important tools to increase the number of electronic transactions that leads to increase the fees and non- shared revenues. Thus, branches should encourage customers to use bank websites to do banking by introducing the above mentioned products.

\section{Quality of Resource}

The assigned preferred weight of quality of resource is 25 scores, which the scores of cost of paid interest to resources and operating costs are 10 and 15 , respectively.

\section{Cost of paid interest to resources (10 score)}

If the quality of resources is not considered and resources are attracted with high rates, the last price of money increases. Therefore, the rate of resource mobilization that is the rate of cost (average cost of interest paid by subsidiaries to depositors until the end of the calculation period) to resources (average resources of subsidiaries by the end of the calculation period) can display the resource quality of the branch.

\section{Operating costs (15 score)}

It is calculated as reducing rate of cost compared to the previous period. The bank's profitability margin of the shared revenues depends on the rate of resource mobilization. This margin is about $2 \%$ in the banking industry. Therefore, given the very high volume of bank resources and given the law of large numbers, the less reduction of resource mobilization can enhance the profitability of banks. So mobilization rate changes (how to calculate the rate of mobilization, is "the quality of resources" in paragraph "1-3") compared to the previous period can be considered as an index for assessing bank's performance.

\section{Measuring the Validity of our proposed Business Model}

In this section, we introduce MPI index in order to test the validity of our proposed business model. In fact, we measure the productivity enhancements for each branch after the implementation of our business model.

\section{Malmquist Productivity Index (MPI)}

To measure productivity, determining output changes and production factors are very important. Changes are easily calculable at firms with single input and single output. But in firms with multiple inputs and outputs, measuring productivity indicators is not definitely easy.

In order to measure changes in productivity, numerical indexes are used to measure the amount of produced output and production factor used in two time periods for a firm. In pairwise comparison, when the two time periods are compared, the index of total factor productivity (TFP) is used. TFP index is calculated for two time periods of $t$ and $t+1$.

One can use the Tronqvist and Fisher technique to calculate TFP. These methods require the prices for all inputs and outputs in the calculation of TFP. Since it is often difficult or impossible to access this information, these methods are limited. But when calculating a TFP index, namely MPI (distance function) was introduced to rectify the weakness of previous indicators. This index does not also need any price information of inputs and outputs [9]. It is worth noting that these distance functions are inverse functions of profitability values based on the Farrell theory (1957).

Fare et al. showed that TFP can be obtained using DEA, which is called MPI [10]. In this index unlike other main indexes of productivity evaluation such as Tronqvist, there is no need to have input and output prices. Also, changes of productivity of total production factors can be separated to technological changes (efficiency frontier-shift) and changes in technical efficiency (catching up the efficient frontier) in MPI.

MPI measures changes in productivity of total factors using two sets of data based on calculating the distance of each set of data in comparison with common technology. To measure MPI, we use the following approach which has been proposed by Fare et al. [10].

$$
\begin{aligned}
& M P I=\frac{\delta^{t+1}\left(\left(x_{0}, y_{0}\right)^{t+1}\right)}{\delta^{t}\left(\left(x_{0}, y_{0}\right)^{t}\right)} \times\left[\frac{\delta^{t}\left(\left(\mathrm{x}_{0}, \mathrm{y}_{0}\right)^{\mathrm{t}}\right)}{\delta^{t+1}\left(\left(x_{0}, y_{0}\right)^{t}\right)} \times \frac{\delta^{t}\left(\left(x_{0}, y_{0}\right)^{t+1}\right)}{\delta^{t+1}\left(\left(x_{0}, y_{0}\right)^{t+1}\right)}\right]^{\frac{1}{2}} \\
& =\left[\frac{\delta^{t}\left(\left(\mathrm{x}_{0}, \mathrm{y}_{0}\right)^{t+1}\right)}{\delta^{t}\left(\left(x_{0}, y_{0}\right)^{t}\right)} \times \frac{\delta^{t+1}\left(\left(x_{0}, y_{0}\right)^{t+1}\right)}{\delta^{t+1}\left(\left(x_{0}, y_{0}\right)^{t}\right)}\right]^{\frac{1}{2}}
\end{aligned}
$$

Based on the value of MPI, we have three cases:

1. If MPI $>1$, it represents the progress in trend of productivity.

2. If $M P I=1$, it represents the productivity remains unchanged.

3. If $\mathrm{MPI}<1$, it represents the declining in trend of productivity.

MPI consists of two components, catch-up and frontier-shift effects. That is,

$\mathrm{MPI}=\mathrm{C}^{\star} \mathrm{F}$ Where

$$
\begin{aligned}
& C=\frac{\delta^{t+1}\left(\left(x_{0}, y_{0}\right)^{t+1}\right.}{\delta^{t}\left(\left(x_{0}, y_{0}\right)^{\mathrm{t}}\right)} \\
& F=\left[\frac{\delta^{t}\left(\left(\mathrm{x}_{0}, \mathrm{y}_{0}\right)^{\mathrm{t}}\right)}{\delta^{t+1}\left(\left(x_{0}, y_{0}\right)^{t}\right)} \times \frac{\delta^{t}\left(\left(x_{0}, y_{0}\right)^{t+1}\right)}{\delta^{t+1}\left(\left(x_{0}, y_{0}\right)^{t+1}\right)}\right]^{\frac{1}{2}}
\end{aligned}
$$

Catch-up effect is the ratio of technical efficiency in period $t+1$ to technical efficiency in period t. Frontier-shift effect includes the geometric mean ratio of performance per unit with respect to the frontier of both technologies $[17,18]$. 
Citation: Karimi B, Davtalab-Olyaie M, Abdali AA (2018) A Suitable Business Model for Bank Branches: Combining Business Model and Malmquist Productivity Index (MPI). Bus Eco J 9: 348. doi: 10.4172/2151-6219.1000348

For calculation $\delta^{\mathrm{P}}\left(\left(\mathrm{x}_{0}, \mathrm{y}_{0}\right)^{\mathrm{K}}\right)(\mathrm{p}, \mathrm{k}=\mathrm{t}, \mathrm{t}+1)$ we use input-oriented CCR model. To do this, we assume that we have $n \operatorname{DMU}_{\mathrm{s}}\left(\mathrm{x}_{\mathrm{j}}, \mathrm{y}_{\mathrm{j}}\right), \mathrm{j}=1, \ldots, \mathrm{n}$ in two times $t$ and $t+1$. We also suppose that $D M U_{j}=\left(x_{i}, y_{j}\right)$ use inputs $x_{j} \varepsilon$ $R^{m}$ to produce q output $y_{j} \varepsilon R^{q}$, and $x_{j}, y_{j}>0, j=1, \ldots, n$. Symbol of $\left(x_{0}, y_{0}\right)$ ${ }^{\mathrm{t}}=\left(\mathrm{x}_{\mathrm{o}}^{\mathrm{t}}, \mathrm{y}_{\mathrm{o}}^{\mathrm{t}}\right)$ and $\left(\mathrm{x}_{0}, \mathrm{y}_{0}\right)^{\mathrm{t}+1}=\left(\mathrm{x}_{0}^{\mathrm{t}+1}, \mathrm{y}_{0}^{\mathrm{t}+1}\right)$ are used to show DMU0 $(0=1, \ldots, \mathrm{m})$ in periods $t$ and $t+1$, respectively. In order to calculate productivity of $\mathrm{DMU}_{0}=\left(\mathrm{x}_{0}, \mathrm{y}_{0}\right)^{\mathrm{k}}$ in period $\mathrm{k}$ according to $\mathrm{p}$ technology we use the following model:

$$
\begin{aligned}
& \delta^{\mathrm{p}}\left(\left(\mathrm{x}_{0}, \mathrm{y}_{0}\right)^{\mathrm{k}}\right)=\min \theta \\
& \text { s.t. } \\
& \sum_{j=1}^{n} \lambda_{j} x_{i j}^{p} \leq \theta x_{i o}^{k} \\
& \sum_{j=1}^{n} \lambda_{j} x_{r j}^{p} \leq \theta x_{r o}^{k} \\
& \lambda_{j} \geq 0
\end{aligned}
$$

Where $\mathrm{k}, \mathrm{p}=\mathrm{t}, \mathrm{t}+1$. Note that when $\mathrm{k}=\mathrm{p}$, the value of technical performance achieved in each stage. We should solve four different models for different $\mathrm{p}$ and $\mathrm{k}$.

\section{Experimental Sample}

The purpose of this section is to apply our proposed approach for a commercial bank in Iran. The population of the study includes all branches of this bank. But only 40 bank branches in 2 provinces in Iran are used as statistical sample. As introduced in the previous section, we consider six indicators in our proposed business model. By consulting with experts, we divide these indicators into two groups, inputs and outputs. In fact, we consider an indicator as output (input) if its increase (reduction) leads to increase the bank's profits. Therefore, we consider operating costs and non-operating costs as inputs; and shared revenues, non-shared revenue, electronic banking ratio and reduction ratio of operating costs as outputs.

At this stage the Bank was asked to provide information about the 40 branches for two periods before and after the implementation of business model. Information after implementing business model of branches is related to three months after implementing this model. Descriptive statistics (including mean, standard deviation, minimum and maximum), inputs and outputs of these 40 branches for both periods are given in Table 1 below.

As explained in the previous section, in order to calculate MPI we must solve four linear programming models. To solve these models, Lingo 11 is used. The results of the implementation of the four linear programming models for each branch are provided in the second to fifth columns of Table 2, respectively. The MPI is also provided in the sixth column of Table 2 for each branch.

The remarkable thing in Table 2 is that the MPI is more than 1 for all bank branches. This indicates that the productivity index of all branches has grown. Therefore, all branches will have higher productivity after implementing business model. This means that our proposed business model has a positive outcome for all bank branches. Accordingly, our proposed business model is an appropriate model in banking area, and so other banks can use it as a perfect scientific model for their branches.

\section{Conclusion}

In this paper, a business model for bank branches is first proposed, which it is applied in a commercial bank in Iran. Then, in order to measure the credibility of our proposed model, an economic index is used to calculate bank productivity known as MPI. The results of the implementation of the MPI show the productivity progress in a sample of branches of this bank. This means that any bank branches in the sample have progress of productivity after implementing our proposed business model. This indicates that the implementation of the business model has been useful for this bank, and consequently, other banks and financial institutions would be able to increase their efficiency

\begin{tabular}{|c|c|c|c|c|}
\hline & Mean & SD. & Min. & Max. \\
\hline \multicolumn{5}{|l|}{ Inputs before implementing model } \\
\hline Operating Costs & $0 / 333$ & $0 / 074702$ & $0 / 131$ & $0 / 463$ \\
\hline Non-Operating Costs & $33 / 975$ & $9 / 447527$ & 15 & 40 \\
\hline \multicolumn{5}{|l|}{ Outputs before implementing model } \\
\hline Shared Revenues & $32,20,13,43,739$ & 21373077665 & $4,90,26,50,345$ & $1,01,34,67,03,074$ \\
\hline non-Shared Revenues & $4,89,54,884$ & $24305531 / 78$ & $90,80,870$ & $11,70,53,451$ \\
\hline E-banking ratio & $0 / 363$ & 0/107747 & $0 / 129$ & $0 / 632$ \\
\hline Reduction ratio of operating costs & $0 / 447$ & 0/078189 & $0 / 279$ & $0 / 576$ \\
\hline \multicolumn{5}{|l|}{ Inputs after implementing model } \\
\hline Operating Costs & $0 / 549$ & $0 / 136264$ & 0/198 & $0 / 813$ \\
\hline Non-Operating Costs & $25 / 85$ & $11 / 37823$ & 15 & 40 \\
\hline \multicolumn{5}{|l|}{ Outputs after implementing model } \\
\hline Shared Revenues & $4,52,85,64,213$ & 2350709924 & $1,06,49,65,552$ & $10,06,10,15,112$ \\
\hline non-Shared Revenues & $13,32,84,249$ & $359132602 / 6$ & $1,49,28,750$ & $2,33,76,87,441$ \\
\hline E-banking ratio & 0/795 & $0 / 065148$ & $0 / 600$ & $0 / 905$ \\
\hline Reduction ratio of operating costs & $0 / 379$ & 0/094277 & $0 / 241$ & $0 / 647$ \\
\hline
\end{tabular}
using our proposed business model. It should be noted that improving or changing business model according to the type of company or organization and changing in used economic models can be considered as the future researches.

Table 1: Descriptive statistics about the inputs and outputs before and after the implementation of the business model of branches. 
Citation: Karimi B, Davtalab-Olyaie M, Abdali AA (2018) A Suitable Business Model for Bank Branches: Combining Business Model and Malmquist Productivity Index (MPI). Bus Eco J 9: 348. doi: 10.4172/2151-6219.1000348

Page 5 of 6

\begin{tabular}{|c|c|c|c|c|c|}
\hline Branches & $\delta^{1}\left(\left(x_{0}, y_{0}\right)^{2}\right)$ & $\delta^{2}\left(\left(x_{0}, y_{0}\right)^{2}\right)$ & $\delta^{1}\left(\left(x_{0}, y_{0}\right)^{1}\right)$ & $\delta^{2}\left(\left(x_{0}, y_{0}\right)^{1}\right)$ & MPI \\
\hline 1 & 2.53 & 1 & 1 & 1.07 & 1.537689 \\
\hline 2 & 3.1 & 0.88 & 0.84 & 0.48 & 2.601129 \\
\hline 3 & 5.09 & 0.87 & 0.91 & 0.61 & 2.824444 \\
\hline 4 & 3.09 & 0.91 & 0.92 & 0.51 & 2.448054 \\
\hline 5 & 1.98 & 0.89 & 0.8 & 0.6 & 1.916051 \\
\hline 6 & 4.4 & 1 & 0.87 & 0.62 & 2.856083 \\
\hline 7 & 2.67 & 1 & 0.75 & 0.45 & 2.81267 \\
\hline 8 & 2.38 & 0.97 & 0.77 & 0.48 & 2.499242 \\
\hline 9 & 11.52 & 1 & 0.99 & 0.49 & 4.873159 \\
\hline 10 & 2.5 & 1 & 0.87 & 0.6 & 2.188441 \\
\hline 11 & 3.06 & 0.94 & 0.8 & 0.46 & 2.795765 \\
\hline 12 & 2.67 & 1 & 0.9 & 0.5 & 2.435844 \\
\hline 13 & 3.09 & 0.92 & 0.79 & 0.42 & 2.927083 \\
\hline 14 & 2.17 & 0.97 & 0.75 & 0.42 & 2.585 \\
\hline 15 & 1.77 & 0.83 & 0.88 & 0.57 & 1.711382 \\
\hline 16 & 2.65 & 0.94 & 0.7 & 0.38 & 3.060174 \\
\hline 17 & 3.15 & 0.99 & 0.79 & 0.43 & 3.029878 \\
\hline 18 & 3.3 & 0.95 & 0.82 & 0.48 & 2.822222 \\
\hline 19 & 2.83 & 0.94 & 0.77 & 0.46 & 2.740519 \\
\hline 20 & 3.09 & 1 & 0.71 & 0.39 & 3.340548 \\
\hline 21 & 1.48 & 0.84 & 0.75 & 0.45 & 1.919259 \\
\hline 22 & 2.65 & 0.85 & 0.8 & 0.45 & 2.501389 \\
\hline 23 & 4.71 & 1 & 1 & 0.59 & 2.825429 \\
\hline 24 & 2.22 & 92 & 0.63 & 0.46 & 2.654735 \\
\hline 25 & 2.36 & 0.97 & 0.75 & 0.43 & 2.664263 \\
\hline 26 & 2.66 & 0.99 & 0.79 & 0.41 & 2.851366 \\
\hline 27 & 2.39 & 1 & 0.86 & 0.61 & 2.134444 \\
\hline 28 & 1.98 & 1 & 1 & 0.69 & 1.693979 \\
\hline 29 & 1.53 & 0.76 & 1 & 0.73 & 1.262092 \\
\hline 30 & 2.23 & 0.94 & 0.94 & 0.61 & 1.911998 \\
\hline 31 & 5.96 & 1 & 0.98 & 0.74 & 2.866779 \\
\hline 32 & 3.98 & 0.94 & 0.91 & 0.95 & 2.080286 \\
\hline 33 & 5.11 & 1 & 0.76 & 0.42 & 4.001096 \\
\hline 34 & 3.26 & 0.92 & 1 & 1.02 & 1.714757 \\
\hline 35 & 5.68 & 0.96 & 1 & 0.82 & 2.578712 \\
\hline 36 & 5.88 & 1 & 1 & 0.62 & 3.079589 \\
\hline 37 & 4.37 & 1 & 0.65 & 0.39 & 4.151946 \\
\hline 38 & 4.46 & 1 & 0.96 & 0.59 & 2.806117 \\
\hline 39 & 3.94 & 0.93 & 0.82 & 0.45 & 3.151203 \\
\hline 40 & 5.17 & 1 & 0.8 & 0.47 & 3.708099 \\
\hline
\end{tabular}

Table 2: Measured productivity index for the 40 branches of the studied bank.

\section{References}

1. Konczal EF (1978) Models Are or Managers, Not Mathematicians. Journal of Systems Management 26: 12

2. Dottore FA (1977) Data Base Provides Business Model. Computerworld 11: 44.

3. Dholakia N, Kshetri N (2003) The global digital divide and mobile business models: Identifying Viable Patterns of e-Development. University of Rhode Island working paper.

4. Petrovic O, Kittl C, Teksten D (2001) Developing Business Models for business In Proceedings of the International conference on Electronic Commerce.

5. Faber E, Ballon P, Bouwman H, Haaker T, Rietkerk O et al., (2003) Designing business models for mobile ICT services. Paper presented to Workshop on concepts metrics \& visualization. 16th Bled Electronic Commerce Conference Transformation, Bled, Slovenia, pp: 9-11.

6. Osterwalder A (2004) The business model ontology: A proposition in a design science approach. Doctoral thesis, Pre'sente'e a l'Ecole des Hautes Etudes Commerciales de l'Universite' de Lausanne.

7. Chesbrough $\mathrm{H}$, Rosenbloom RS (2002) The Role of the Business Model in capturing value from Innovation: Evidence from XEROX Corporation's
Technology Spinoff Companies. Industrial and Corporate Change 11: 529-555.

8. Teece DJ (2010) Business model, business strategy, and innovation. Long Range Planning 43: 172-194.

9. Malmquist S (1953) Index numbers and indifference surfaces. Trabajos de Estatistica 4: 209-242.

10. Färe R, Grosskopf S, Norris M, Zhang Z (1994) Productivity growth, technical progress, and efficiency changes in industrialized countries. American Economic Review 84: 66-83.

11. Charnes A, Cooper WW, Rhodes E (1978) Measuring the efficiency of decision making units. European Journal of Operational Research 2: 429-444.

12. Cooper WW, Seiford LM, Tone K (1999) Data Envelopment Analysis: A Comprehensive Text with Models, Applications, References and DEA-Solver Software. Kluwer Academic Publisher.

13. Camanho AS, Dyson RG (1999) Efficiency, size, benchmarks and targets for bank branches: An application of data envelopment analysis. Journal of the Operational Research Society 50: 903-915.

14. Hartman TE, Storbeck JE, Byrnes $P$ (2001) Allocative efficiency in branch banking. European Journal of Operational Research 134: 232-242. 
Citation: Karimi B, Davtalab-Olyaie M, Abdali AA (2018) A Suitable Business Model for Bank Branches: Combining Business Model and Malmquist Productivity Index (MPI). Bus Eco J 9: 348. doi: 10.4172/2151-6219.1000348

Page 6 of 6

15. Shyu J, Chiang T (2012) Measuring the true managerial efficiency of bank branches in Taiwan: A three-stage DEA analysis. Expert Systems with Applications 39: 11494-11502.

16. Lin TT, Lee CC, Chiu TF (2009) Application of DEA in analyzing a bank's operating performance. Expert Systems with Applications 36: 8883-8891.
17. Banker RD, Charnes A, Cooper WW (1984) Some models for estimating technical and scale inefficiencies in data envelopment analysis. Management Science 30: 1078-1092.

18. Caves DW, Christensen LR, Diewert WE (1982) The Economic Theory of Index Numbers and the Measurement of Input, Output, and Productivity. Econometrica 50: 1393-1414. 